\title{
Multi-band algorithms for the estimation of chlorophyll concentration in the Chesapeake Bay
}

\author{
Alexander Gilerson ${ }^{1}$, Michael Ondrusek ${ }^{2}$, Maria Tzortziou ${ }^{3}$, Robert Foster ${ }^{1}$, Ahmed El-Habashi $^{1}$, Surya \\ Prakash Tiwari ${ }^{4}$ and Sam Ahmed ${ }^{1}$ \\ ${ }^{1}$ Optical Remote Sensing Laboratory, the City College of the City University of NY, NY, NY, USA \\ ${ }^{2}$ NOAA/NESDIS/STAR, College Park, MD, USA \\ ${ }^{3}$ Department of Earth and Atmospheric Sciences, the City College of the City University of NY, NY, \\ NY, USA \\ ${ }^{4}$ Red Sea Research Center at KAUST, Kingdom of Saudi Arabia
}

\begin{abstract}
Standard blue-green ratio algorithms do not usually work well in turbid productive waters because of the contamination of the blue and green bands by CDOM absorption and scattering by non-algal particles. One of the alternative approaches is based on the two- or three band ratio algorithms in the red/NIR part of the spectrum, which require 665, $708,753 \mathrm{~nm}$ bands (or similar) and which work well in various waters all over the world. The critical $708 \mathrm{~nm}$ band for these algorithms is not available on MODIS and VIIRS sensors, which limits applications of this approach. We report on another approach where a combination of the $745 \mathrm{~nm}$ band with blue-green-red bands was the basis for the new algorithms. A multi-band algorithm which includes ratios $\operatorname{Rrs}(488) / \operatorname{Rrs}(551)$ and $\operatorname{Rrs}(671) / \operatorname{Rrs}(745)$ and two band algorithm based on Rrs671/Rrs745 ratio were developed with the main focus on the Chesapeake Bay (USA) waters. These algorithms were tested on the specially developed synthetic datasets, well representing the main relationships between water parameters in the Bay taken from the NASA NOMAD database and available literature, on the field data collected by our group during a 2013 campaign in the Bay, as well as NASA SeaBASS data from the other group and on matchups between satellite imagery and water parameters measured by the Chesapeake Bay program. Our results demonstrate that the coefficient of determination can be as high as $\mathrm{R}^{2}>0.90$ for the new algorithms in comparison with $\mathrm{R}^{2}=0.6$ for the standard OC3V algorithm on the same field dataset. Substantial improvement was also achieved by applying a similar approach (inclusion of $\operatorname{Rrs}(667) / \operatorname{Rrs}(753)$ ratio) for MODIS matchups. Results for VIIRS are not yet conclusive.
\end{abstract}

Keywords: chlorophyll-a algorithm, multiband algorithm, coastal waters, field data, MODIS, VIIRS

\section{INTRODUCTION}

Chlorophyll-a concentration [Chl], one of the main products retrieved from ocean color satellite imagery, is usually estimated from the ratio of reflectances in the blue-green bands ${ }^{1}$, which provides reasonable accuracy for open ocean waters, though much less so in optically complex coastal waters because of contamination of the blue and green reflectance signals from CDOM absorption and absorption and scattering by non-algal particles.

Recent advances in the development of atmospheric correction models over coastal zones have inspired further development of retrieval algorithms for turbid productive waters. One such approach is based on the two- or three band ratio algorithms in the red/NIR part of the spectrum, which require $665,708,753 \mathrm{~nm}$ bands (or similar) ${ }^{2,3}$. Recent studies by many research groups around the world showed that relatively universal two- and three bands algorithms developed by us ${ }^{4}$ work well in various waters in the US, Israel, China, Russia, etc. ${ }^{5-8}$ without any additional tuning. The critical 708 $\mathrm{nm}$ band for these algorithms was available on MERIS and is expected to be on the OLCI sensor of the Sentinel 3 satellite but is not available on MODIS and VIIRS sensors, which limits applications of this approach.

The Chesapeake Bay is the largest estuary in the $\mathrm{US}^{9}$ with a surface area of over $11,000 \mathrm{~km}^{2}$. It is a highly productive estuary with strong spatial and temporal gradients in water quality and composition. Multiple water parameters are monitored by the Chesapeake Bay Program ${ }^{9}$ including concentrations of chlorophyll-a [Chl]. The parameters are used in various models with a range of applications, including fisheries, water quality, and forecasts of harmful algal blooms and

Remote Sensing of the Ocean, Sea Ice, Coastal Waters, and Large Water Regions 2015, edited by

Charles R. Bostater, Stelios P. Mertikas, Xavier Neyt, Proc. of SPIE Vol. 9638, 96380A

(C) 2015 SPIE · CCC code: $0277-786 X / 15 / \$ 18 \cdot$ doi: $10.1117 / 12.2195725$

Proc. of SPIE Vol. 9638 96380A-1 
sea nettles. Satellite observations provide a broader and synoptic coverage of the distribution of parameters through Ocean Color retrieval algorithms, which should be properly validated with in-situ data. With the launch of JPSS Visible Infrared Imaging Radiometer Suite (VIIRS) sensor in 2011, and several similar sensors planned for launch during the next decade, there has been a strong interest to develop reliable algorithms for coastal waters using VIIRS bands. This work is focused primarily on the development and validation of [Chl] algorithms that use very limited set of VIIRS bands for the Chesapeake Bay with a possible expansion to other coastal areas.

A number of manuscripts have been published on the biological and optical properties, satellite retrievals, algorithms and climatology for the Chesapeake Bay ${ }^{10-21}$ and several [Chl] algorithms were proposed ${ }^{13,14,18}$. Most of them are not directly applicable to the VIIRS sensor.

The VIIRS band set in the visible -NIR part of the spectrum includes 410, 443, 488, 551, 671 and $745 \mathrm{~nm}$ bands. Despite recent improvements, atmospheric correction in coastal areas remains one of the main challenges because of issues related to satellite calibration, aerosol models, absorbing aerosols, and impact of $\mathrm{NO}_{2}{ }^{19,22}$. Recent work on the validation of the VIIRS sensor based on data from the Long Island Sound Coastal Observatory (LISCO) located in coastal Western Long Island Sound which is a part of NASA AERONET and AERONET Ocean Color networks, showed that VIIRS and MODIS remote sensing reflectances are often associated with significant errors at 412 and $443 \mathrm{~nm}$ bands ${ }^{23}$. Accordingly, these bands should be excluded from algorithms for coastal waters which further limits options for algorithm development.

In this paper we compare the performance of the standard OC algorithms with an algorithm based on the red/NIR ratio ${ }^{24}$ as well as a new approach that uses a combination of the blue-green and red-NIR (including $745 \mathrm{~nm}$ ) bands. Several multi-band algorithms were developed and tested using synthetic datasets, well representing the main relationships between water parameters in the Bay, field data and matchups between satellite imagery and water parameters measured by the Chesapeake Bay program.

\section{SYNTHETIC, FIELD AND SATELLITE DATA}

A synthetic dataset for over 1000 stations was developed based on a four component bio-optical model ${ }^{25,26}$ which includes pure water, chlorophyllous particles with a defined concentration of chlorophyll-a [Chl], non-algal particles (NAP) characterized by their concentration, and colored dissolved organic matter defined by its absorption coefficient at $443 \mathrm{~nm}$ ag(443). Relationships to determine scattering and absorption coefficients of these components were similar to those in previous models ${ }^{25,26}$ with the main parameters taken in the ranges available from NOMAD dataset and previous field measurements ${ }^{11,16}$ typical for the Chesapeake Bay. In addition, statistical relationships between phytoplankton, CDOM and non-algal particles absorptions at $443 \mathrm{~nm}$ available from NOMAD were also taken into account to limit simulations to the most realistic combinations of water parameters. The total absorption and backscattering calculated from the bio-optical model were then used as an input to simulate the remote sensing reflectance above water as a function of parameter $u=b_{b} /\left(a+b_{b}\right)$, where $b_{b}$ and a are respectively the total backscattering and absorption coefficients; to connect parameter $u$ with the above water remote sensing reflectance instead of usual second order polynomial ${ }^{27} \mathrm{a}$ fourth order polynomial ${ }^{28}$ was used in the relationship as needed to properly account for bidirectional effects in a wide range of $u$ values under consideration assuming vertical viewing:

$$
\operatorname{Rrs}=0.54 * 0.0512 *\left(1+4.6659 * \mathrm{u}-7.8387 * \mathrm{u}^{2}+5.4571 * u^{3}\right)(1.1098 * 1.4021) * u
$$

An empirical correction term in the form of $(1+0.0004 *[\mathrm{Chl}])$ was applied to Rrs at $671 \mathrm{~nm}$ band to take into account the small impact of the chlorophyll fluorescence. Rrs were simulated for the wavelengths 443, 488, 551, 665, 671, 708, 745 and $753 \mathrm{~nm}$ which include central wavelengths for VIIRS, MODIS and partially MERIS satellite sensors to allow the testing of algorithms based on blue-green as well as red-NIR bands. The ranges of concentrations in the dataset were as following: $[\mathrm{Chl}]=1-80 \mathrm{mg} / \mathrm{m}^{3}$ with the normal distribution between 1 and $25 \mathrm{mg} / \mathrm{m}^{3}$ (1000 points) and random distribution for higher values ( 60 points), $[\mathrm{NAP}]=2-49 \mathrm{~g} / \mathrm{m}^{3}$, ag443 $=0.1-2.0 \mathrm{~m}^{-1}$ determined by the bio-optical model through the relationships with the phytoplankton absorption at $443 \mathrm{~nm}$.

Field data were primarily from measurements conducted at 43 stations in the Chesapeake Bay during a field campaign in August 2013, hereafter referred to as the CCNY dataset. At each station, we measured upwelling radiance $\operatorname{Lu}\left(\lambda, 0^{-}\right)$using a fiber bundle placed just beneath the water surface and connected to a GER spectroradiometer (SpectraVista, NY). The down- welling radiance above the surface $\operatorname{Ld}(\lambda, 0+)$ was measured by pointing the same probe bundle onto a Spectralon 
plate and the downwelling irradiance determined as $\operatorname{Ed}(\lambda, 0+)=A^{*} \pi \operatorname{Ld}(\lambda, 0+)$ where $A=0.99$ is the reflectance factor of the Spectralon plate (Labsphere, NH), constant for the whole spectrum. The underwater remote sensing reflectance rrs is then calculated as $\operatorname{Lu}\left(\lambda, 0^{-}\right) / \operatorname{Ed}\left(\lambda, 0^{-}\right) \mathrm{sr}^{-1}$ which was transformed to the above surface Rrs by multiplying by a 0.54 factor $^{29}$. Chlorophyll-a concentrations [Chl] from the samples that were collected during the field campaign were determined according to NASA protocol for fluorometric chlorophyll-a determination ${ }^{30}$. In addition, field data from the GEO-CAPE experiment, $2011^{18}$ were downloaded from the SeaBASS NASA database.

VIIRS satellite data was acquired with a strict filtering procedure ${ }^{31}$. Satellite data used for match-up comparison with the Chesapeake Bay program in-situ [Chl] data were all extracted from the $3 \times 3$ pixel box centered at the specific site locations where the in-situ $[\mathrm{Chl}]$ measurements were made. These data were, then, spatially averaged and compared with the in-situ [Chl]. VIIRS level 2 files do not contain Rrs at $745 \mathrm{~nm}$, so SeaWiFS Data Analysis System (SeaDAS), version 7.2, was used in the processing. In this matchup comparison, we excluded any individual pixel that was flagged by at least one of these conditions: land, cloud, failure in atmospheric correction, stray light, bad navigation quality, both high and moderate glint, negative Rayleigh-corrected radiance, viewing angle larger than $60^{\circ}$, and solar zenith angle larger than $70^{\circ}$. In addition, at least 5 out of the 9 pixels in the box had to be valid (not flagged) in order to use the $3 \times 3$ pixel box, otherwise all nine pixels were discarded. Moreover, data of any individual pixels that had negative waterleaving radiance in any of the wavelengths were also excluded from spatial averaging. Furthermore, any individual pixel with its center location more than $2 \mathrm{~km}$ away from the in-situ site location was also excluded from spatial averaging. 128 matchups were acquired for 2012 - May 2015; among them 73 data points had a time difference between satellite and in-situ measurements less than 4 hours.

MODIS (July 2002-December 2011) Level-0 data were obtained from the NASA GSFC ocean color archive (http://oceancolor.gsfc.nasa.gov/) by the group of the University of South Florida ${ }^{18}$ and processed with the most updated at that time calibration and algorithms using SeaDAS, version 6.2 software. The 1-km resolution Level-2 data products included spectral $\operatorname{Rrs}(\lambda)$, Chla determined from the default empirical algorithm (OC3 for MODIS), and the Level-2 quality control flags (e.g., atmospheric correction warning, stray light, etc.). This dataset which was kindly shared with the CCNY group contains 1139 data points. Maps with the sampling points for the CCNY field campaign and VIIRS data are shown in Fig. 1.

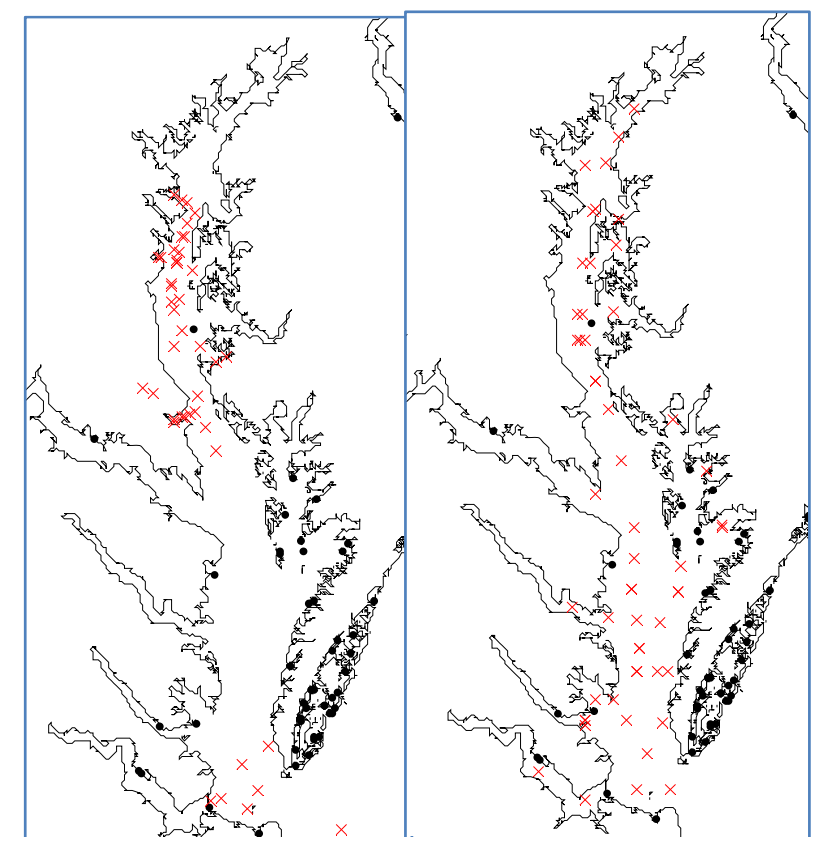

Figure 1. Maps of sampling (CCNY dataset) and matchups (VIIRS - Chesapeake Bay program) 


\section{MULTI-BAND ALGORITHMS, TESTS ON THE SYNTHETIC DATA}

As discussed above, the OC blue bands 412 and $443 \mathrm{~nm}$ are not currently reliable in coastal waters and should be excluded from the algorithms. This leaves a very small number of bands for VIIRS which are at 488, 551, 671 and 745 center wavelengths. In addition to the standard OC3V algorithm, which uses the ratio of Rrs(488)/Rrs(551), several other combinations were explored. Reasonable results were achieved using neural network (NN) algorithms ${ }^{32}$ on the synthetic and field data but we found that adjustment of these algorithms to the satellite data was not straightforward. At the same time we found that for the field data the algorithm which uses red-NIR bands ${ }^{4}$, below referred to as G10, substantially outperformed OC3V algorithm as shown in Fig. 2. G10 algorithm is written as in equation 17.2

$$
[\mathrm{Chl}]=(35.75 *(\operatorname{Rrs} 708 / \operatorname{Rrs665})-19.30)^{\wedge} 1.124
$$

Results of Fig. 2 also confirm very high data consistency between measured reflectances and [Chl] in the CCNY dataset. Following results in Fig. 2, several algorithms which contain combinations of all or some of available bands in the all parts of the spectra have been explored.
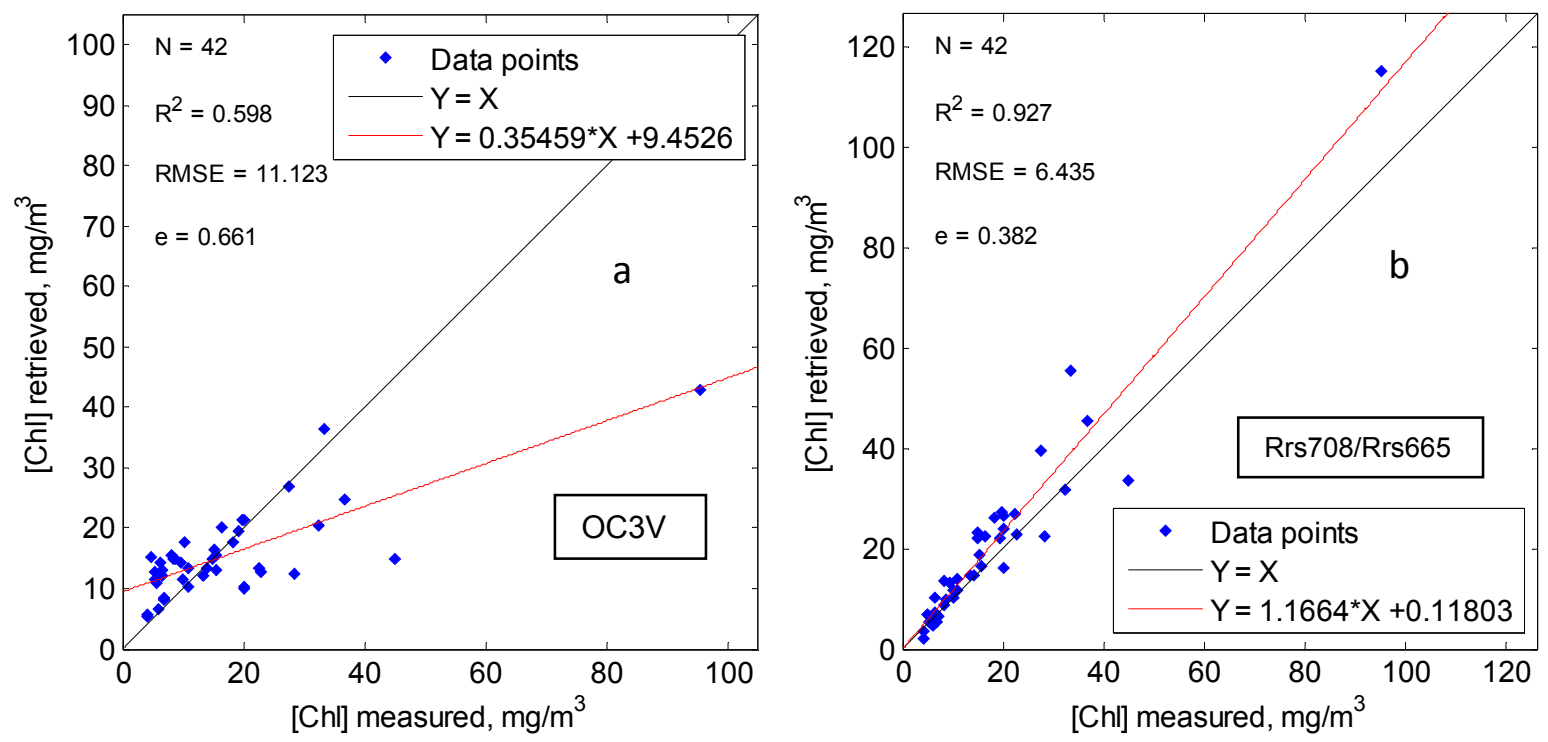

Figure 2. Performance of a)OC3V and b)Red-NIR bands algorithms on the CCNY field

We found a very strong correlation $\left(\mathrm{R}^{2}=0.99\right)$ between $\mathrm{Rrs}$ at 708 and $745 \mathrm{~nm}$ bands and, thus, we explored replacing the $708 \mathrm{~nm}$ band in the [Chl] retrieval with $745 \mathrm{~nm}$ band. Obviously, Rrs values at $745 \mathrm{~nm}$ are quite low which can lead to additional uncertainties for the field and satellite data. After analysis of multiple combinations of bands, two algorithms yielded the most consistent and promising results: a) a combination of two ratios $\mathrm{R} 1=\operatorname{Rrs}(488) / \operatorname{Rrs}(550)$ and $\mathrm{R} 2=$ $\operatorname{Rrs}(671) / \operatorname{Rrs}(745)$ and $b)$ just one $\operatorname{Rrs}(671) / \operatorname{Rrs}(745)$ ratio. The first algorithm is in the form of

$$
\text { chl_calc1 }=10^{\wedge}(\mathrm{a} 1+\mathrm{a} 2 * \mathrm{R} 1+\mathrm{a} 3 * \mathrm{R} 2
$$

where a1, a 2 and $\mathrm{a} 3$ are the fitting coefficients.

The second algorithm is based on Eq. $(16)^{4}[\mathrm{Ch}]=\left[a_{w}\left(\lambda_{1}\right) R 2-a_{w}\left(\lambda_{2}\right)\right] / a_{p h}^{*}(665)$, where $a_{w}\left(\lambda_{1}\right)$ is the pure water absorption coefficient at 708 or $753 \mathrm{~nm}$ and $a_{w}\left(\lambda_{2}\right)$ is the water absorption coefficient at $665 \mathrm{~nm}, a_{p h}^{*}(665)$ is the phytoplankton specific absorption at $665 \mathrm{~nm}$. This equation was adjusted for 671 and $745 \mathrm{~nm}$ bands and additional two fitting coefficients $\mathrm{t} 1$ and $\mathrm{t} 2$ were included for tuning purposes:

$$
\text { chl_calc2 }=((2.459 *(\mathrm{t} 1 * 1 / \mathrm{R} 2)-0.439+\mathrm{t} 2) / 0.022)^{\wedge} 1.124
$$

Tuning was performed using the MATLAB nonlinear least-squares (data-fitting) procedure. Comparison of results for 
OC3V, G10 and two new algorithms on the synthetic dataset are shown in Fig. 3. The set of coefficients for Fig. 3c was: $\mathrm{a} 1=2.8230$ a2 $=-0.2758$ a3 $=-0.4007$ with small variations due to the randomness of input values. Similarly, $\mathrm{t} 1=$ 1.1794 and $\mathrm{t} 2=-0.0740$. As expected, the performance of OC3V (Fig. 3a) was poor. The three other algorithms had a similar performance with an $\mathrm{R}^{2}$ near 0.9 , with the last two algorithms requiring additional tuning. G10 was used in its standard form of Eq (1). In addition to $\mathrm{R}^{2}$ root mean square error RMSE and the relative error $\mathrm{e}=\mathrm{RMSE} / \mathrm{mean}$ ([Chl] measured) are shown.
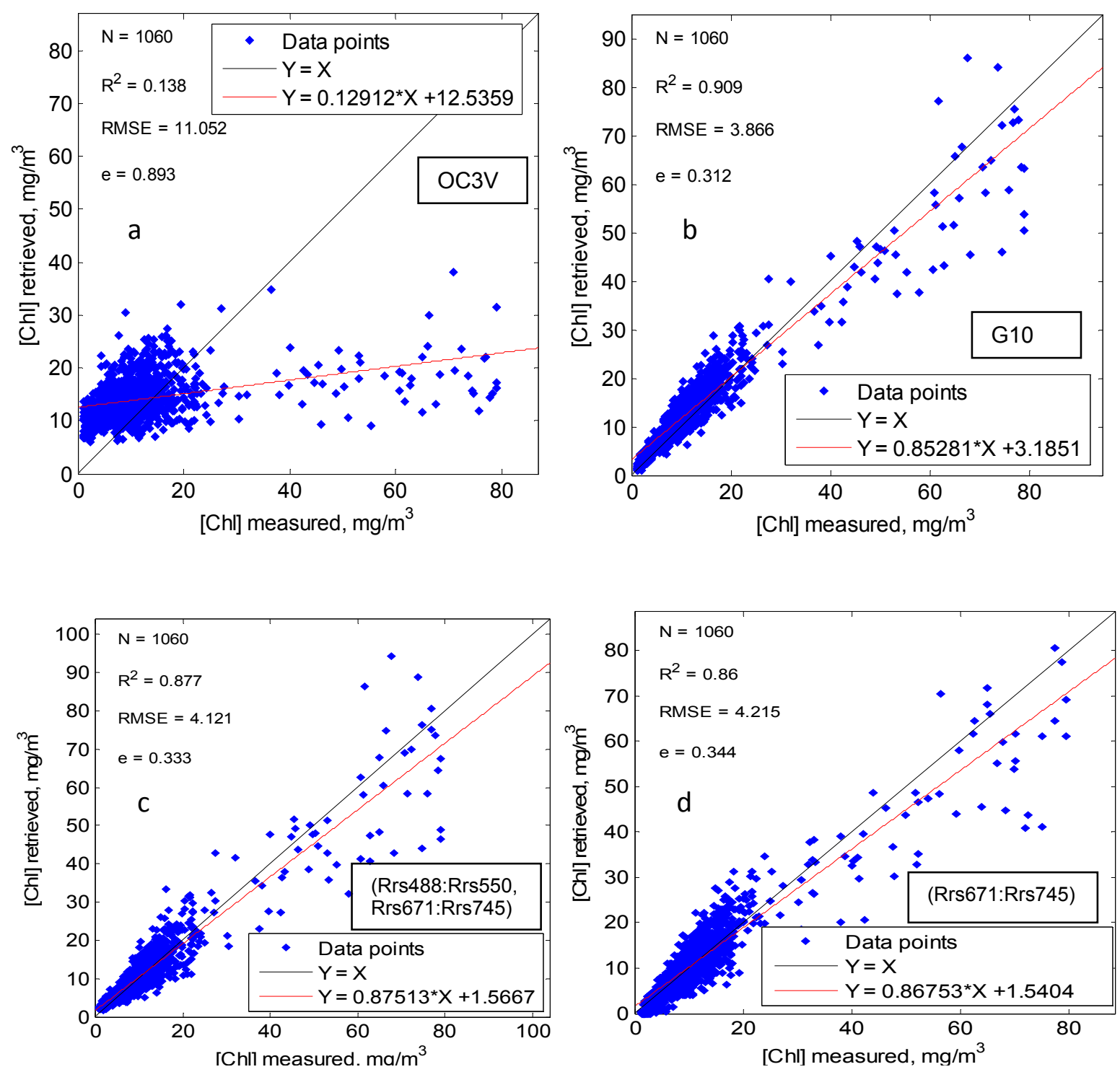

Figure 3. Performance of a) $\mathrm{OC} 3 \mathrm{~V}, \mathrm{~b}) \mathrm{G} 10, \mathrm{c}) \mathrm{Eq}(2)$ and d)Eq(3) algorithms on the synthetic data.

\section{TESTING ALGORITHMS ON THE FIELD DATA}

The performance of OC3V and G10 algorithms on the field data was demonstrated above in Fig. 2; new algorithms which contain $745 \mathrm{~nm}$ band were also tested with results in Fig. 4 showing the performance ( $\mathrm{R}^{2}, \mathrm{RMSE}$ and e) similar to the one on the synthetic dataset. Synthetic and field datasets obviously have some differences, so the coefficients were different as well. 

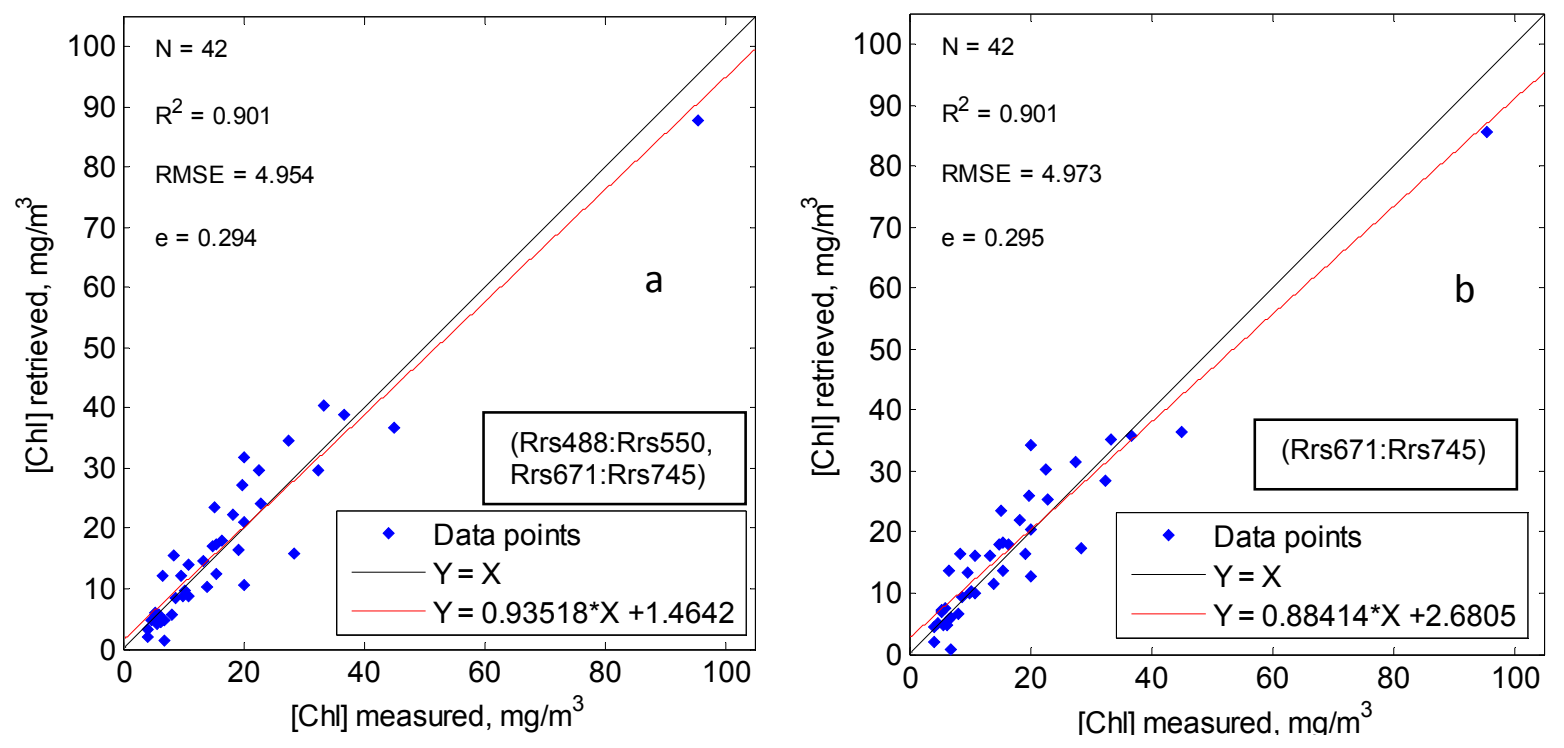

Figure 4. Performance of a) $\mathrm{Eq}(2)$ and b)Eq(3) algorithms on the CCNY field data.

To determine the applicability of the algorithms with these coefficients to the other field data we used results of measurements from the 2011 NASA Chesapeake Bay oceanographic field campaign with Discover-AQ performed as part of NASA's preparation efforts for the GEO-CAPE (Geostationary for Coastal and Air pollution events) ocean color mission downloaded from the SeaBASS database (PI-C. Hu). Reflectances and [Chl] concentrations were measured in this cruise together with other parameters. The significant difference with CCNY dataset (where reflectances were measured just below the surface and did not contain any sky component) is that in the USF dataset reflectances were measured from above the surface and then corrected for the sky component using the methodology $y^{18,33,34}$. This approach makes reflectances, especially their low values in NIR, quite sensitive to the correction procedures. After the analysis of these data minor additional correction was applied: reflectance of 0.00016 was added to all bands bringing the data to the approximately the same area in $\mathrm{R} 2-[\mathrm{Chl}]$ coordinates as for the CCNY dataset. The performance of OC3V, G10 and two new algorithms is presented in Fig. 5 showing lower $\mathrm{R}^{2}$ for all algorithms but still the performance of G10 and new algorithms was much better than OC3V.
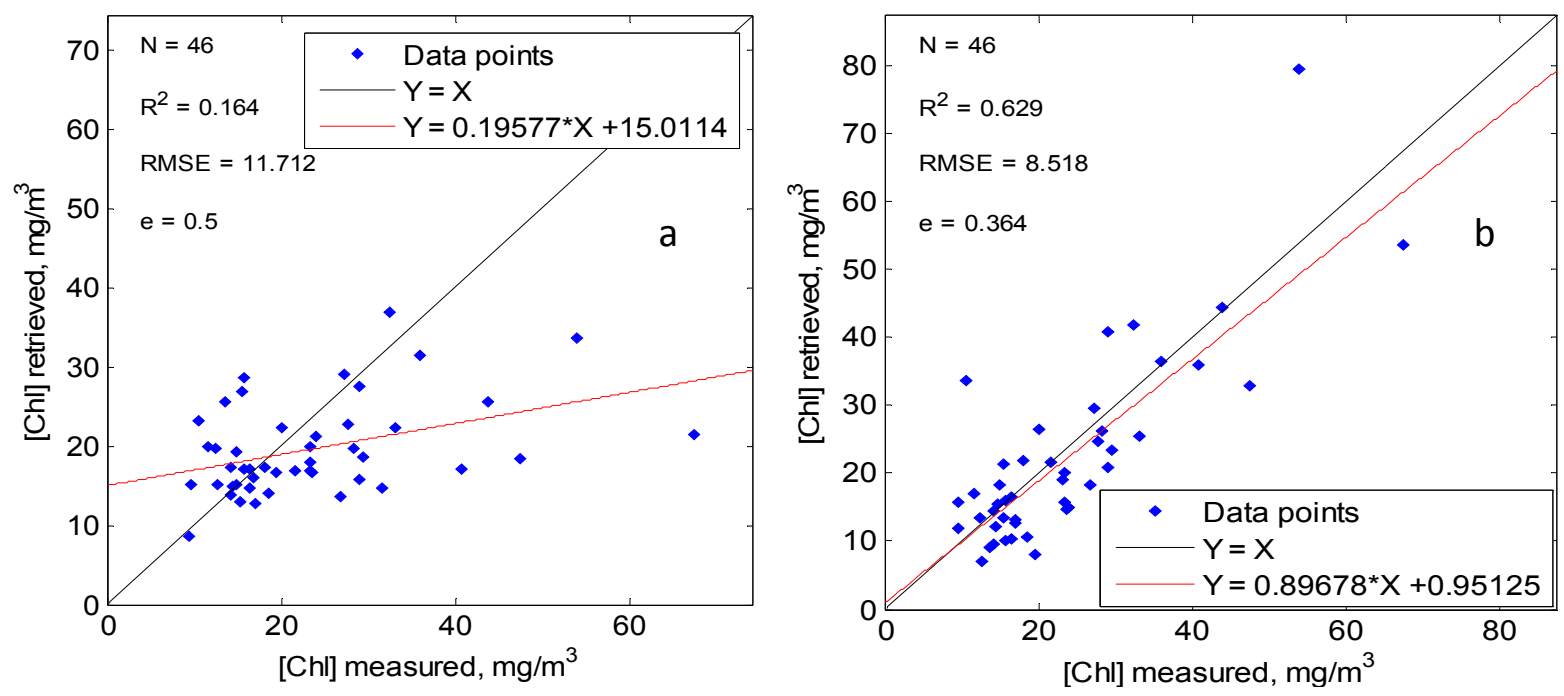

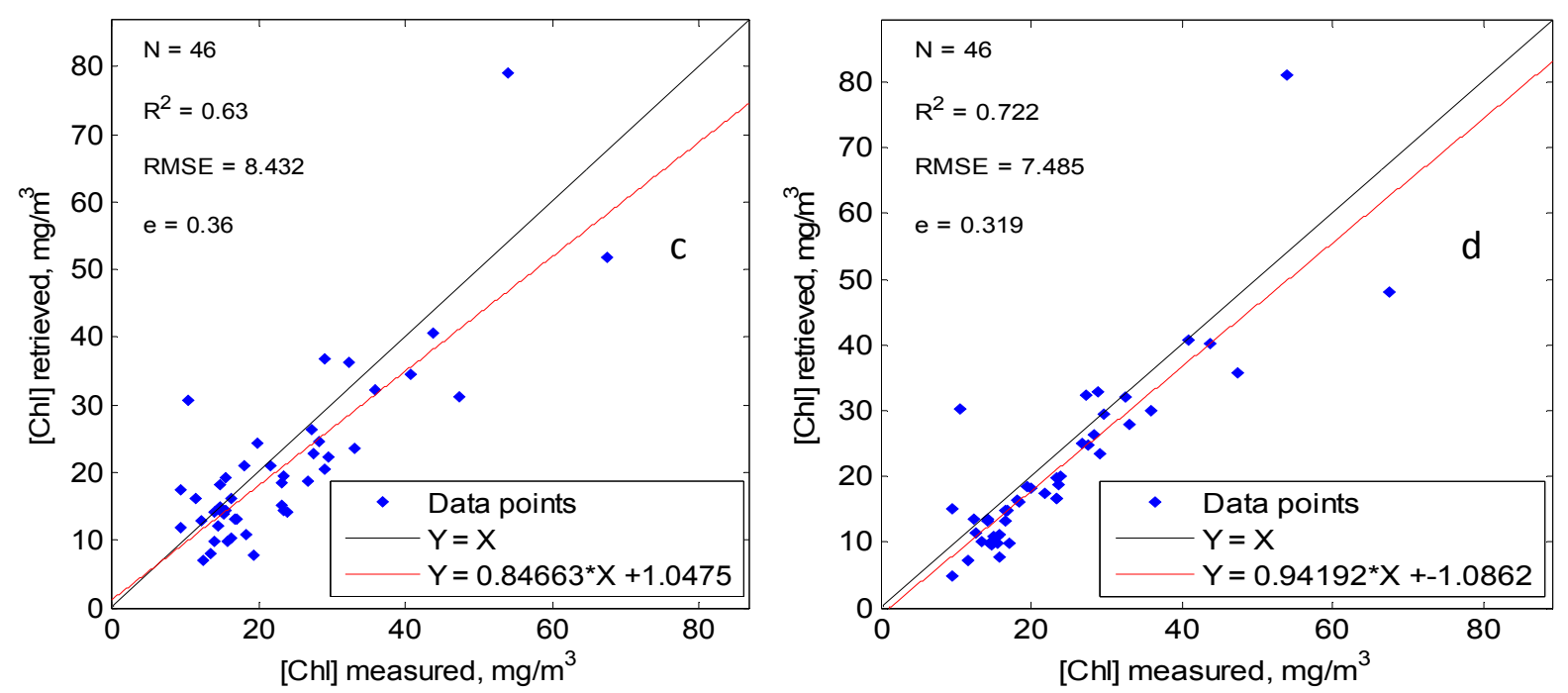

Figure 5. Performance of a) OC3V, b) G10, c) Eq(2) and d) Eq(3) algorithms on the USF field data.

\section{PERFORMANCE OF THE ALGORITHMS ON THE SATELLITE DATA}

Proposed algorithms with $745 \mathrm{~nm}$ band were further tested on the VIIRS satellite data and compared with OC3V. We first tested the performance of the algorithms using a time difference between the satellite data acquisition and in-situ measurements of 4 hours which resulted in 73 match-ups.

Results are shown in Fig. 6. In this case the performance of all three algorithms was similar. It should be noted that the performance of OC3V on VIIRS data was considerably better than OC3M on MODIS data where $\mathrm{R}^{2}$ was about $0.012^{19}$, most likely due to the VIIRS better spatial resolution.
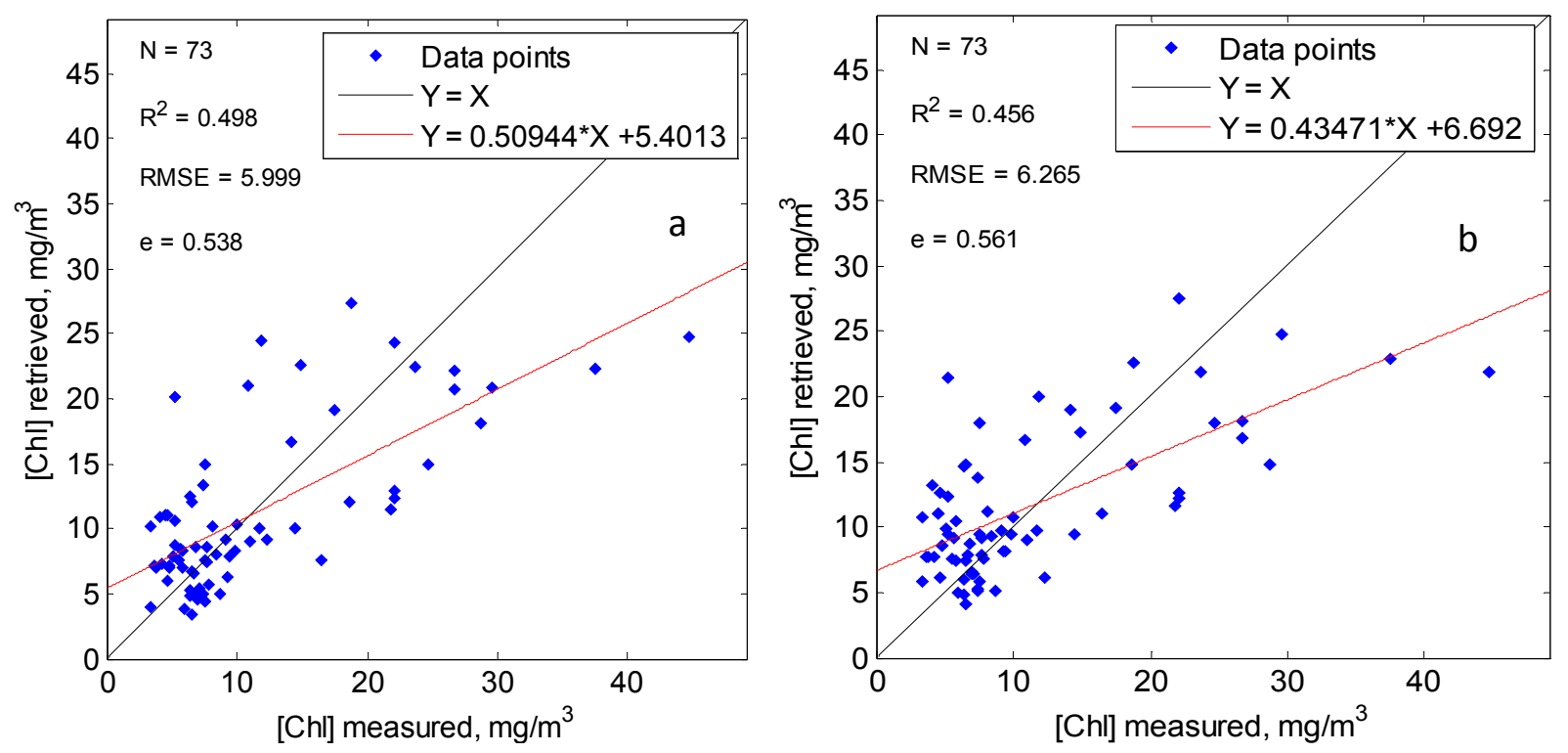


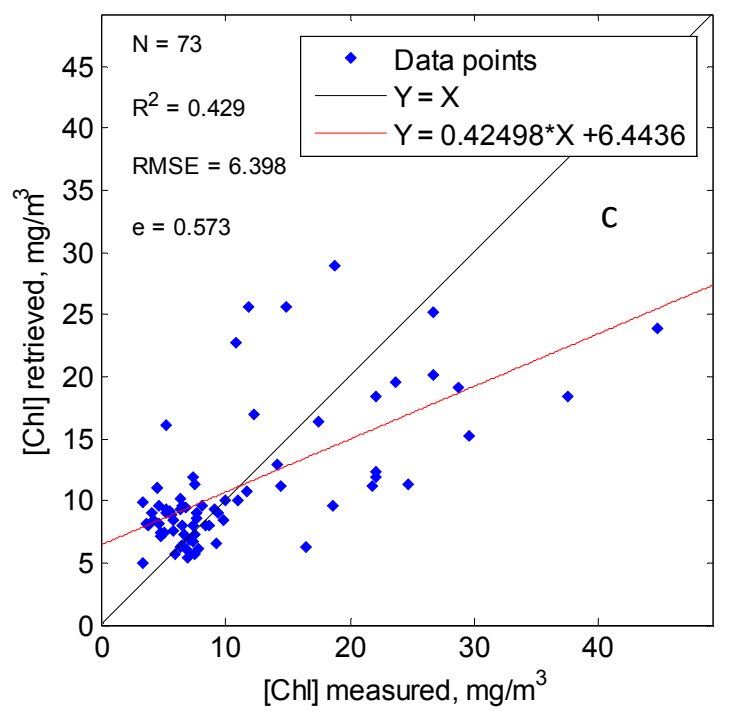

Figure 6. Performance of a) $\mathrm{OC} 3 \mathrm{~V}$, b) $\mathrm{Eq}(2)$ and c) $\mathrm{Eq}(3)$ algorithms on VIIRS data

It should be noted that strict limitations discussed above ${ }^{31}$ that were applied for the selection of the satellite data, resulted in excluding most of the measurements near the shores that are characterized by higher [Chl] and CDOM absorption. This is most likely one of the reasons of the increase in the OC3V performance. Similar performance of OC3V and algorithms of $\mathrm{Eq}(2)$ and $\mathrm{Eq}(3)$, which is not consistent with the results from simulations and field data, means probably that this performance is partially limited by mismatches between the satellite and in situ data due to the spatial and temporal variability of water parameters in the Bay.

Increase of the time difference between satellite and in-situ measurements to 12 hours decreased the algorithm performance but not dramatically with $\mathrm{R}^{2}=0.4$ for OC3V, 0.32 for Eq (2) and Eq (2) algorithms. Similar tests on MODIS data of Eq(2) algorithm with 488, 550, 667 and 754 bands led to the results presented in Fig. 7 demonstrating significant improvement of $\mathrm{R}^{2}$ in comparison with OC3M. Better results $\left(\mathrm{R}^{2}=0.43\right)$ were achieved for MODIS with $\operatorname{Rrs}(531) / \operatorname{Rrs}(667)^{18}$ or $\operatorname{Rrs}(531) / \operatorname{Rrs}(678)^{35}$ but these combinations are not available on VIIRS.

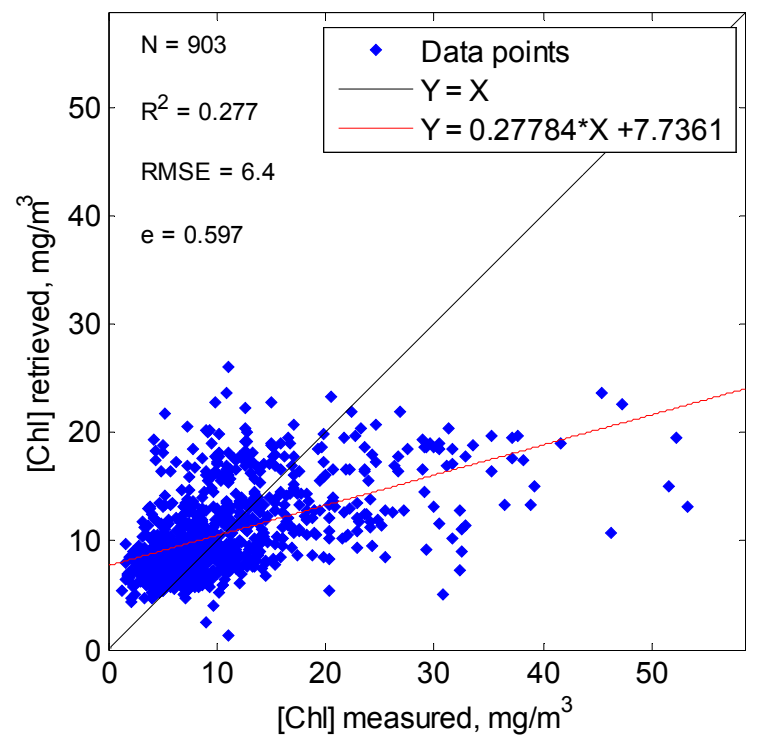

Figure 7. Performance of Eq (2) algorithm on MODIS data. 
Fig. 8 shows the comparison of average reflectance spectra for all synthetic, field and satellite data described above. Taking into account very different approaches the match looks very reasonable at most of bands. At the same time the main difference is observed near $671 \mathrm{~nm}$ band but this band is most sensitive to the [Chl] and thus average reflectance values should be very dependent on the weight of the Chesapeake Bay areas sampled in each set with typically higher [Chl] values should correspond to the lower Rr671 due to the increased [Chl] absorption. It should be noted that the mean [Chl] values were (in $\mathrm{mg} / \mathrm{m}^{3}$ ): simulations - 12.3, field CCNY - 16.8, field USF - 23.4, VIIRS - 11.2 and MODIS - 10.7, which suggests that the satellite data are not fully consistent with the field and synthetic data and should be further monitored and analyzed.

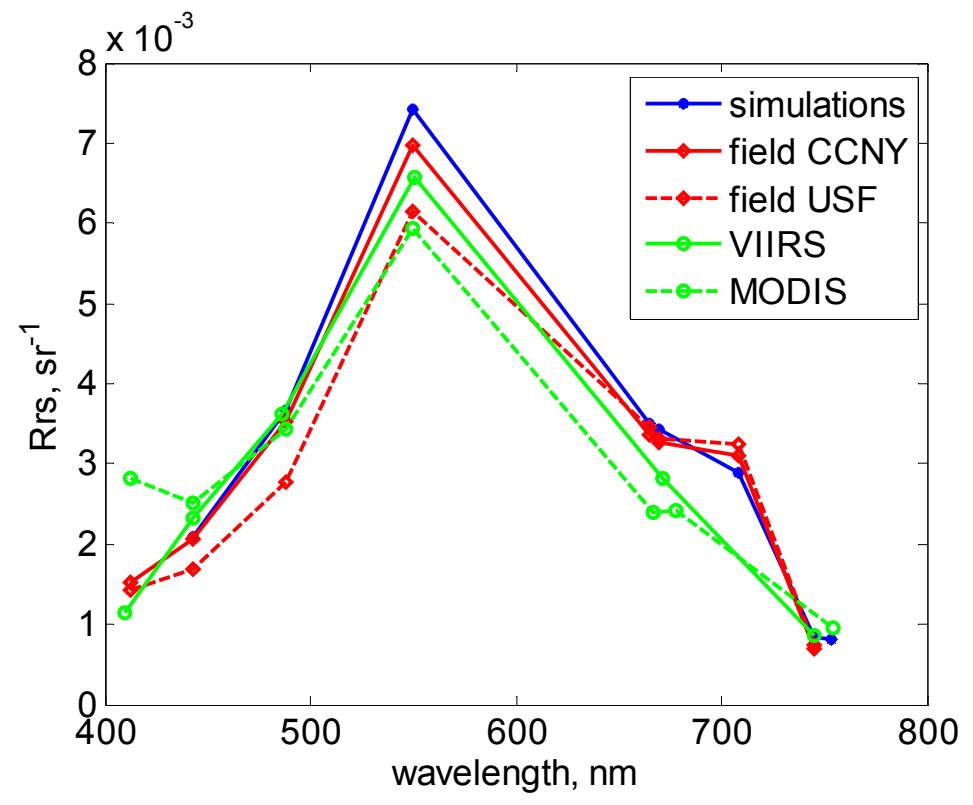

Figure 8. Average reflectance spectra for the synthetic, field and satellite data.

Examples of the [Chl] maps from VIIRS satellite imagery processed using OC3V and two new algorithms are shown in Fig. 10 and they are similar to each other with $[\mathrm{Chl}]<5 \mathrm{mg} / \mathrm{m}^{3}$ in the Lower Bay, $5-15 \mathrm{mg} / \mathrm{m}^{3}$ in the Middle Bay and above $15 \mathrm{mg} / \mathrm{m}^{3}$ in some areas of the Upper Bay and near the coast.
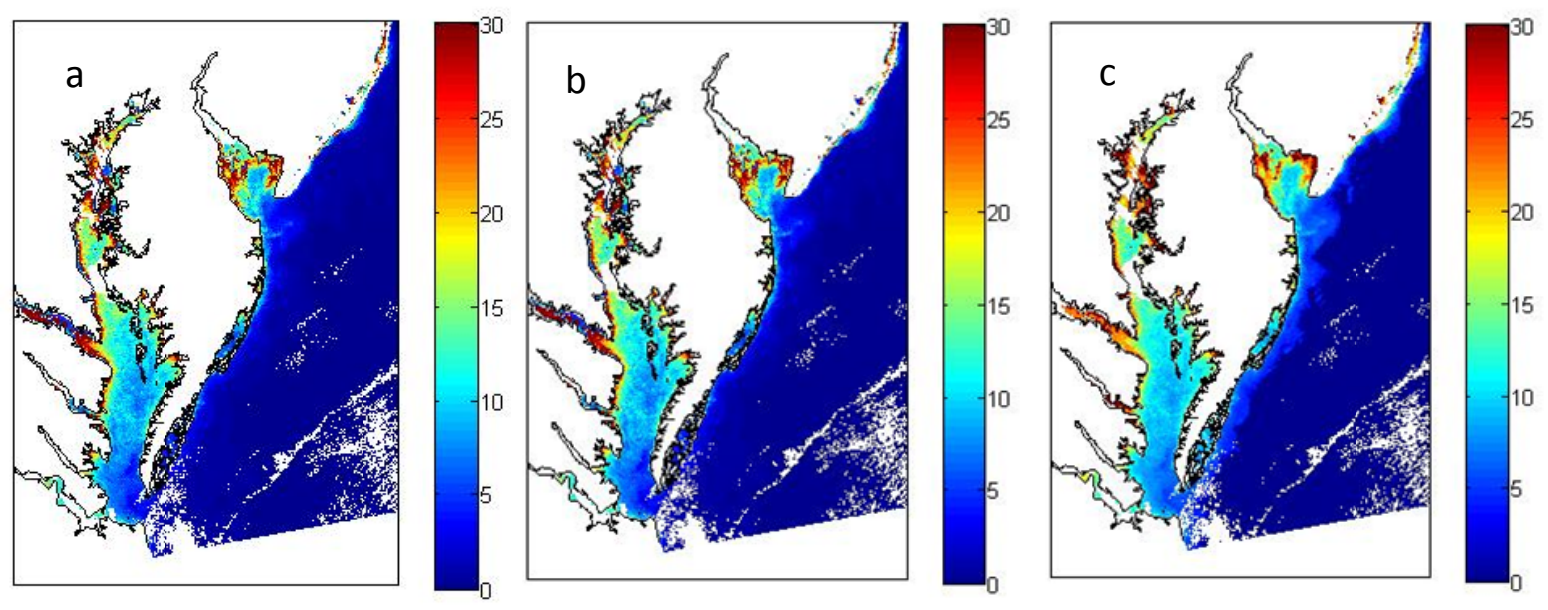

Figure 9. VIIRS [Chl] maps for the Chesapeake Bay: a) OC3 V, b) Eq (2), c) Eq (3). Numbers in the color bars are [Chl] in $\mathrm{mg} / \mathrm{m}^{3}$. 


\section{TSS ALGORITHM FOR THE CHESAPEAKE BAY}

The concentration of total suspended solids (TSS) is also of interest for the Chesapeake Bay. Previous studies ${ }^{17}$ connected TSS to the normalized water leaving radiance at $645 \mathrm{~nm}$ and through NAP absorption to Rrs at $670 \mathrm{~nm}^{13}$. In this work additional set of VIIRS images was downloaded from the NASA OC site which corresponded to the TSS insitu data measured by the Chesapeake Bay program. It was found that a very strong correlation exists between TSS and VIIRS Rrs at $745 \mathrm{~nm}$ as shown in Fig. 10 which marks this algorithm as a good candidate for the estimation of TSS.

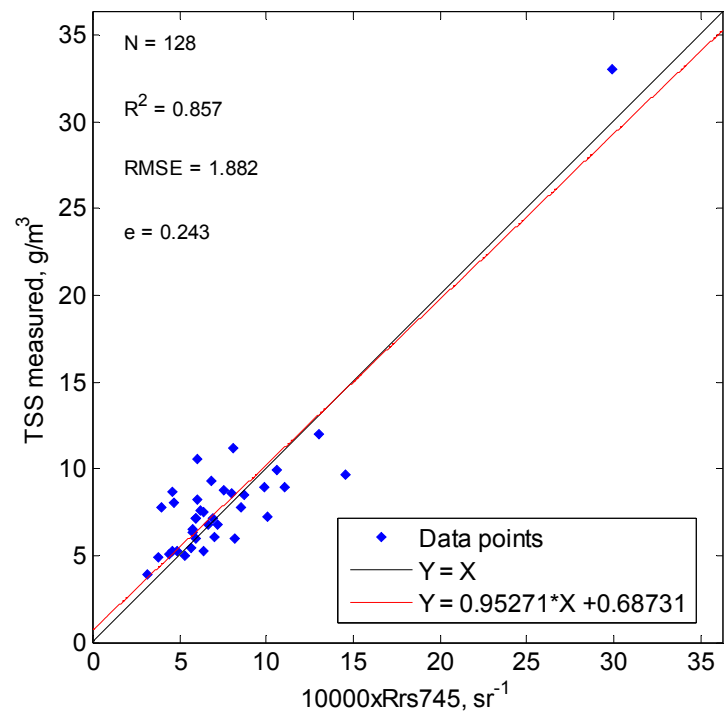

Figure 10. Relationship between Rrs(745) and measured TSS from VIIRS.

\section{CONCLUSIONS}

Two algorithms which contain a combination of two ratios $\mathrm{R} 1=\operatorname{Rrs}(488) / \operatorname{Rrs}(550)$ and $\mathrm{R} 2=\operatorname{Rrs}(671) / \operatorname{Rrs}(745)$ and just one $\operatorname{Rrs}(671) / \operatorname{Rrs}(745)$ ratio are proposed for the remote estimation of the chlorophyll-a concentration in the Chesapeake Bay, their performance is evaluated on the synthetic, field and satellite data and compared with the one of the standard blue-green ratio as well as red-NIR ratio algorithms. It is shown that the proposed algorithms perform well on the synthetic, field and MODIS satellite data. There is relatively small number of reliable VIIRS data points that are currently available for the matchups with in-situ data but first results demonstrate the reasonable performance $\left(\mathrm{R}^{2}\right.$ near 0.5 ) of the standard OC3V algorithm, especially in comparison with MODIS, which can be most likely attributed to the better VIIRS spatial resolution. Similar performance of OC3V and algorithms of Eq(2) and Eq(3), which is not consistent with the results from simulations and field data, can be probably attributed to mismatches between the satellite and in situ data due to the spatial and temporal variability of water parameters in the Bay which limit algorithms performance. More data are necessary to make reliable conclusions.

In addition, it was found that $\operatorname{Rrs}(745)$ can be a very good proxy for the estimation of the concentration of total suspended solids (TSS).

\section{ACKNOWLEDGMENTS}

This work was partially supported by the grants from National Oceanic and Atmospheric Administration and JPSS Risk Reduction Program. 


\section{REFERENCES}

[1] J. E. O'Reilly, and 24 Coauthors, "SeaWiFS Postlaunch Calibration and Validation Analyses, Part 3," in NASA Tech. Memo. 2000-206892, Vol. 11, S. B. Hooker and E. R. Firestone, eds., (NASA Goddard Space Flight Center, Greenbelt, MD) 49 pp. (2000).

[2] A.A. Gitelson, "The peak near $700 \mathrm{~nm}$ on reflectance spectra of algae and water: Relationships of its magnitude and position with chlorophyll concentration," Int. J. of Remote Sens. 13, 3367-3373 (1992).

[3] G. Dall'Olmo and A. A. Gitelson, "Effect of bio-optical parameter variability and uncertainties in reflectance measurements on the remote estimation of chlorophyll-a concentration in turbid productive waters: modeling results," Appl. Opt. 20, 3577-3592 (2006).

[4] A.A. Gilerson, A.A. Gitelson, J. Zhou, D. Gurlin, W. J. Moses, I. Ioannou, I., S. Ahmed, "Algorithms for remote estimation of chlorophyll-a in coastal and inland waters using red and near infrared bands," Optics Express, 18, 24109-24125 (2010).

[5] D. Gurlin, A. A. Gitelson, W. J. Moses, "Remote estimation of chl-a concentration in turbid productive waters Return to a simple two-band NIR-red model?" Remote Sensing of Environment 115, 3479-3490 (2011).

[6] Y. Z. Yacobi, W.J. Moses, S. Kaganovsky, B. Sulimani, B.C. Leavitt, \& A.A. Gitelson, "NIR-red reflectancebased models for chlorophyll-a estimation in mesotrophic inland and coastal waters: Lake Kinneret case study," Water Research, 45, 2428-2436 (2011).

[7] Linhai Li, Lin Li, K. Song, Y. Li, K. Shi and Z. Li, "An improved analytical algorithm for remote estimation of chlorophyll-a in highly turbid waters," Environ. Res. Lett. 6, 034037 (2011)

[8] W. J Moses, A. A Gitelson, S. Berdnikov, V. Saprygin, V. Povazhnyi," Operational MERIS-based NIR-red algorithms for estimating chlorophyll-a concentrations in coastal waters-The Azov Sea case study," Rem. Sens. of Env., 121, 118-124 (2012).

[9] www.chesapeakebay.net/wquality.htm

[10] L.W. Harding Jr., A. Magnuson, M.E. Mallonee, "Bio-optical and remote sensing observations in Chesapeake Bay," Estuarine, Coastal and Shelf Science 62, 75-94 (2005).

[11] A. Magnuson, L.W. Harding Jr., M.E. Mallonee, J.E. Adolf, "Bio-optical model for Chesapeake bay and the middle Atlantic bight," Estuarine, Coastal and Shelf Science 61, 403-424 (2004).

[12] M. Tzortziou, J.R. Herman, C.L. Gallegos, P.J. Neale, A. Subramanian, L. W. Harding, "Bio-optics of the Chesapeake Bay from measurements and radiative transfer closure," Estuarine, Coastal and Shelf Science, 68, 348362 (2006).

[13] M. Tzortziou, A. Subramaniam, J. Herman, C. Gallegos, P.Neale, L. Harding, "Remote sensing reflectance and inherent optical properties in the Mid Chesapeake Bay," Estuarine Coastal and Shelf Science, 72(1): 1632.DOI:10.1016/j.ecss.2006.09.018 (2007)

[14] A.A. Gitelson, J. Schalles, C.M. Hladik, "Remote chlorophyll-a retrieval in turbid productive estuarine: Chesapeake Bay case study. Rem. Sens. of Env. 109, 464-472 (2007).

[15] P. J. Werdell, S. W. Bailey, B. A. Franz, L. W. Harding Jr., G. C. Feldman, C. R. McClain, "Regional and seasonal variability of chlorophyll-a in Chesapeake Bay as observed by SeaWiFS and MODIS-Aqua," Rem. Sens. of Env. 113, 1319-1330 (2009).

[16] C.L. Gallegos, P. J. Werdell, and C. R. McClain, "Long-term changes in light scattering in Chesapeake Bay inferred from Secchi depth, light attenuation, and remote sensing measurements," J. Geophys. Res., 116, C00H08, doi:10.1029/2011JC007160 (2011).

[17] M. Ondrusek, E. Stengel, C. Kinkade, R. Vogel, P. Keegstra, C. Hunter, C. Kim, "The development of a new optical total suspended matter algorithm for the Chesapeake Bay," Rem. Sens. of Env. 119, 243-254. doi:10.1016/j.rse.2011.12.018 (2012).

[18] C. Le , C. Hu, J. Cannizzaro , H. Duan , "Long-term distribution patterns of remotely sensed water quality parameters in Chesapeake Bay," Estuarine, Coastal and Shelf Science, 128, 93-103 (2013).

[19] S. Son, M. Wang, "Water properties in Chesapeake Bay from MODIS-Aqua measurements," Remote Sensing of Environment 123, 163-174 (2012).

[20] W. Shi, M. Wang, L. Jiang, "Tidal effects on ecosystem variability in the Chesapeake Bay from MODIS-Aqua," Rem. Sens. of Env. 138, 65-76 (2013). 
[21] G. Zheng, D. Stramski, and P. M. DiGiacomo, “ A model for partitioning the light absorption coefficient of natural waters into phytoplankton, nonalgal particulate, and colored dissolved organic components: A case study for the Chesapeake Bay," J. Geophys. Res. Oceans, 120, 2601-2621, doi: 10.1002/2014JC010604 (2015).

[22] M. Tzortziou M., J. R Herman, Z. Ahmad, C.P. Loughner, N. Abuhassan, A. Cede, "Atmospheric NO2 Dynamics and Impact on Ocean Color Retrievals in Urban Nearshore Regions", Journal of Geophysical Research-Oceans. DOI: 10.1002/2014JC009803 (2014).

[23] S. Hlaing, T. Harmel, A. Gilerson, R. Foster, A. Weidemann, R. Arnone, M. Wang, S. Ahmed, "Evaluation of the VIIRS ocean color monitoring performance in coastal regions, "Remote Sensing of Environment, "139, 398-414 (2013).

[24] R.P. Stumpf, M.A. Tyler, "Satellite detection of bloom and pigment distributions in estuaries," Remote Sens. of Environ. 24, 385-404 (1988).

[25] Remote Sensing of Inherent Optical Properties: Fundamentals, Tests of Algorithms, and Applications. Lee, Z.-P. (ed.), Reports of the IOCCG, No. 5, Dartmouth, Canada (2006).

[26] A. Gilerson, J. Zhou, S. Hlaing, I. Ioannou, J. Schalles, B. Gross, F. Moshary, S. Ahmed, "Fluorescence component in the reflectance spectra from coastal waters. Dependence on water composition," Optics Express, 15, 15702-15721 (2007).

[27] Z. Lee, K.L. Carder, R. Arnone, "Deriving inherent optical properties from water color: a multiband quasianalytical algorithm for optically deep water," Appl. Opt. 41, 5755-5772 (2002).

[28] P. Gege and A. Albert, "A tool for inverse modeling of spectral measurements in deep and shallow waters" in Remote Sensing of Aquatic Coastal Ecosystem Processes: Science and Management Applications, L.L. Richardson and E.F. LeDrew, eds. Chap. 4, Springer, 2006.

[29] A. Morel and B. Gentili, "Diffuse reflectance of oceanic waters. II. Bidirectional aspects," Appl. Opt. 32, 68646872 (1993).

[30] Ocean Optics Protocols for Satellite Ocean Color Sensor Validation, Fargion, G.S., Mueller, J.L. (Eds.), NASA/TM-2003-21621 (2003).

[31] S. Hlaing, A. Gilerson, R. Foster, M. Wang, R. Arnone and S. Ahmed, "Radiometric calibration of ocean color satellite sensors using AERONET-OC data," Optics Express, 22, 23385 - 23401 (2014).

[32] I. Ioannou, A. Gilerson, M. Ondrusek, R. Foster, A. El-Habashi, K. Bastani, S. Ahmed, "Algorithms for the remote estimation of chlorophyll-a in Chesapeake Bay," Proc. of SPIE 9111 (2014).

[33] C. D. Mobley, "Estimation of the remote-sensing reflectance from above-surface measurements," Applied Optics 38(36), 7442-7455 (1999).

[34] Z. Lee, K. Carder, C. Mobley, R. Steward, and J. Patch, "Hyperspectral remote sensing for shallow waters. II. Deriving bottom depths and water properties by optimization," Applied Optics 38, 3831-3843 (1999).

[35] C. Le, personal communications. 